\title{
Study of the interocclusal distortion in impressions taken with different types of closed-mouth trays and two types of impression materials
}

\author{
José-Félix Mañes-Ferrer ${ }^{1}$, Eduardo-José Selva-Otaolaurruchi ${ }^{2}$, Carmina Parra-Arenós ${ }^{3}$, Isabel Selfa-Bas ${ }^{4}$ \\ ${ }^{1}$ Dentistry Degree Coordinator. Universidad Europea de Madrid. Seconded Center Valencia \\ ${ }^{2}$ Full Professor. Faculty of Medicine and Dentistry. University of Valencia \\ ${ }^{3}$ Associate Professor. Faculty of Health Sciences. Dentistry. University CEU Cardenal Herrera. Valencia. Masters in Prosthetics. \\ University of Valencia \\ ${ }^{4}$ Private dental practice in Valencia, Masters in Prosthetics. University of Valencia
}

Correspondence:

Universidad Europea de Madrid.

Seconded Center Valencia.

C/ General Elío 8

46010 Valencia

jfmanes@estema.org

Received: 14/04/2009

Accepted: 05/06/2009

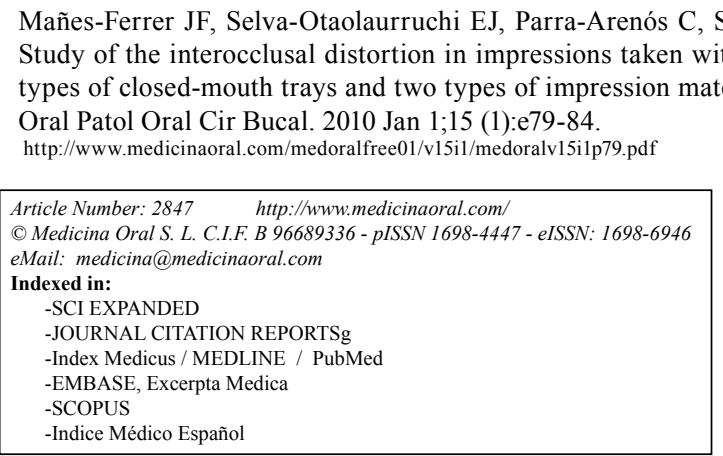

\begin{abstract}
The aim of this study was to compare different types of impression trays for the closed-mouth impression technique, using two different types of impression material. For this study, five different types of impression trays were used with two different types of impression materials, one of addition silicone and the other of polyether. We designed a model used for taking the impressions and for measuring interocclusal distortion. The results obtained show that the impression trays COE (GC (R) GC America INC. Alsip) and Premier (Premier (R), Premier Dental Products Co. Canada) show a lesser degree of interocclusal distortion when taking closed-mouth impressions. In terms of impression materials, the polyether was the one that produced the best results. From a clinical point of view, our study shows that the use of these types of trays is absolutely recommendable when used according to the clinical indications for which they have been designed; that said, we must not fail to consider that selecting the proper type of tray is also important.
\end{abstract}

Key words: Impression trays, closed-mouth impressions, interocclusal distortion, addition silicone, polyether.

\section{Introduction}

The dual-arch, closed-mouth impression technique has been used for more than two decades; it was described for the first time by Pensler A(1). As early as 1977, Costello affirmed that: "an impression obtained in this manner is easily describable and the results are consistently precise"(2).

The dual-arch impression technique became popular at the end of the 1980's when the trays from Triple Tray
(Premier ${ }^{\circledR}$, Premier Dental Products Co. Canada) were introduced in 1983, in which the front section was added to the traditional rear impression, from canine to canine. Its advantages include: saving time, both for the dentist as well as for the patient; comfort of the patient; saving impression material; predictable occlusion of the maxillary and mandibular models, and because they are disposable trays, they eliminate the cleaning process and the possibility of transmitting diseases (3). 
In this procedure, an impression is taken of the carved teeth, adjoining teeth and antagonist teeth, such that the models of the prepared teeth, antagonist teeth and occlusal relationship may be taken in one single impression. The technique is not complicated and reduces the time of the seating, cost and possibility of error. Dualarch trays may be used with any impression material: polyether, addition silicone, condensation silicone or polysulfate (3).

It is an impression technique that is indicated if the patient's set of teeth are intact; if the restoration affects a single crown, inlay or onlay, bordered by teeth that are intact; if the patient is able to bite down in an intercuspal position without obstructions; and if the antagonist teeth have the occlusal surfaces intact.

However, this technique also has its contraindications, such as is the case of: patients who require restoration of the entire arch, patients who have alterations of the vertical dimension of occlusion or who have a maximum unstable intercuspidation (4).

In this type of impressions, the patient has to close the mouth by biting down on a specially designed tray, in which a membrane or web divides the tray into two compartments: maxillary and mandibular. As far as the occlusion is concerned, the exactness of the models depends on whether the patient bites down into maximum intercuspidation. With the tray in the mouth and the membrane between the teeth, the patient's sense of touch may be altered and can interfere in the maximum intercuspidation. It is precisely this problem and the different designs of the trays that exist on the market that have prompted us to study how such designs might influence the result of the models and to study and compare two types of impression material.

The objective of this work is to analyze and measure the interocclusal distortion that results between the models obtained with different closed-mouth partial trays, using two different types of impression materials.

\section{Material and Methods}

The impressions taken were carried out on a dual-arch impression die (Fig.1A), with a standard preparation in both the maxillary and the mandible, which will help in making subsequent measurements. (Fig.1B)

Two variables were taken into account:

* The type of trays: 5 different types of dual-arch trays, four of which are plastic and one that is metallic, including: Triple Tray (Premier $\AA$, Premier Dental Products Co. Canada), COE (GC® GC America INC. Alsip), Big Bite Tray (Bossworth ${ }^{\circledR}$ Bosworth Co. England), Multitray (Henry Shein ${ }^{\circledR}$ Henry Schein INC. Melville NY), Bite- Tray (R\&S $\mathbb{R} \& S$ France), the last one being the metallic design. (Fig.1C)

* The impression material: Two types of addition silicone viscosity (Elite HD+® Heavy Body made of plaster and Light Body in a spray gun, both from the manufacturer Zhermack) (Zhermack SpA, Rome, Italy) and polyether (Permadyne ${ }^{\circledR}$ Garant 2:1, low consistency in a spray gun, and Permadyne ${ }^{\circledR}$ Penta $\mathrm{H}$ made of Pentamix, both from the manufacturer 3M) (3M Co. St Paul, MN, USA).
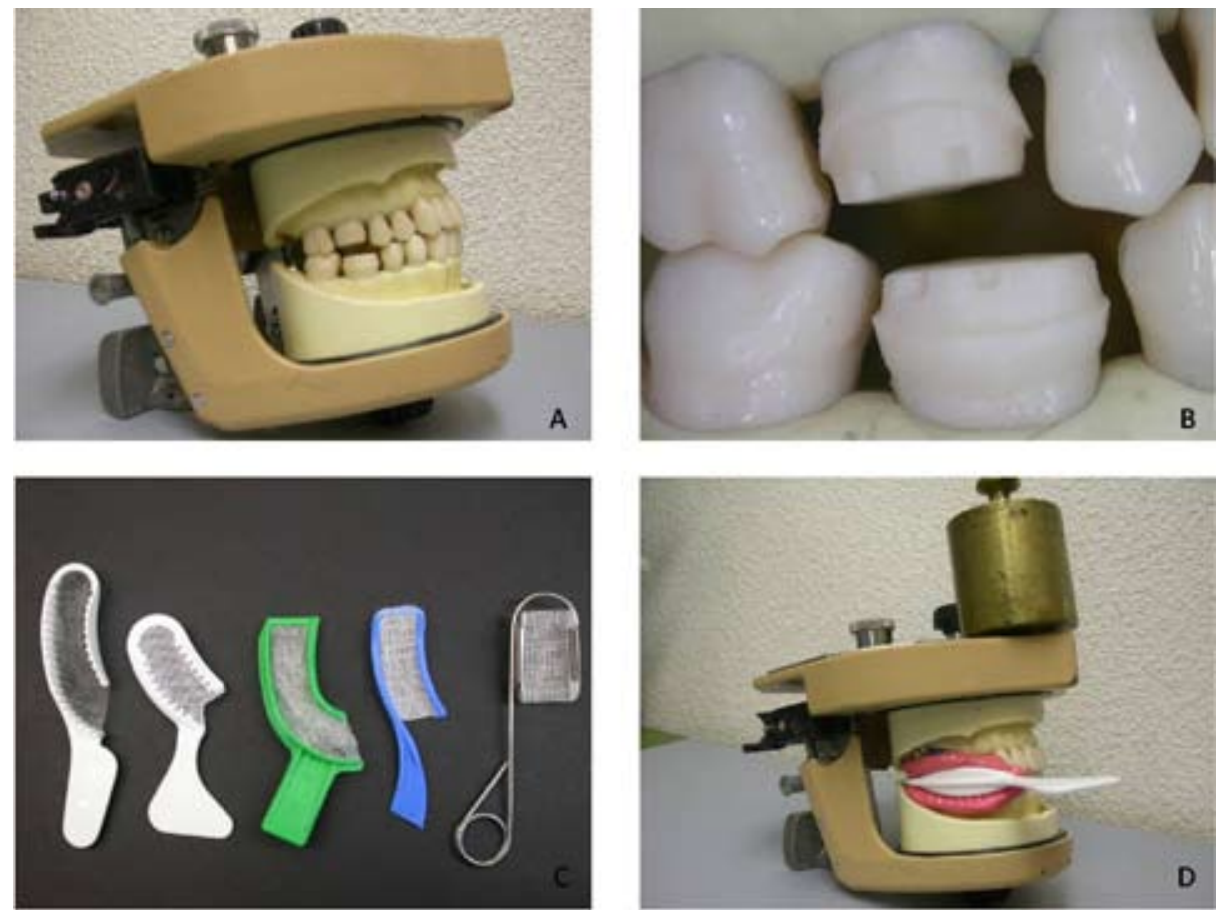

Fig. 1. Material used in experimentation. Types of dental preparations and trays used. 
A total of 6 impressions were made with each one of the trays. The impressions included 3 made with silicone material and 3 with polyether material, obtaining a total of 30 impressions of the model, with the molar prepared to be analyzed.

The material with a fluid consistency is applied over the model. The tray and the model are then coated with the thick consistency and we close the impression die in a stable and reproducible position. A constant, stable and reproducible pressure of 1 kilo is applied over the impression as the material is drying, and this process is repeated for the rest of the impressions (Fig.1D). Once the material of the impression has dried, the tray is emptied with 100 gr. of type III stone plaster from the manufacturer Proal (Schmidt SA, Spain) and $28 \mathrm{ml}$ of distilled water blended in a vacuum mixer for 30 seconds.

According to the Wilson and Werrin protocol (3), first we empty the side that is being worked on, which in this case, corresponds to the upper arch. Once the plaster has dried, and according to the protocol established for this task, some groves have to be made on the dried side, a plaster cast separator is applied and we proceed to empty
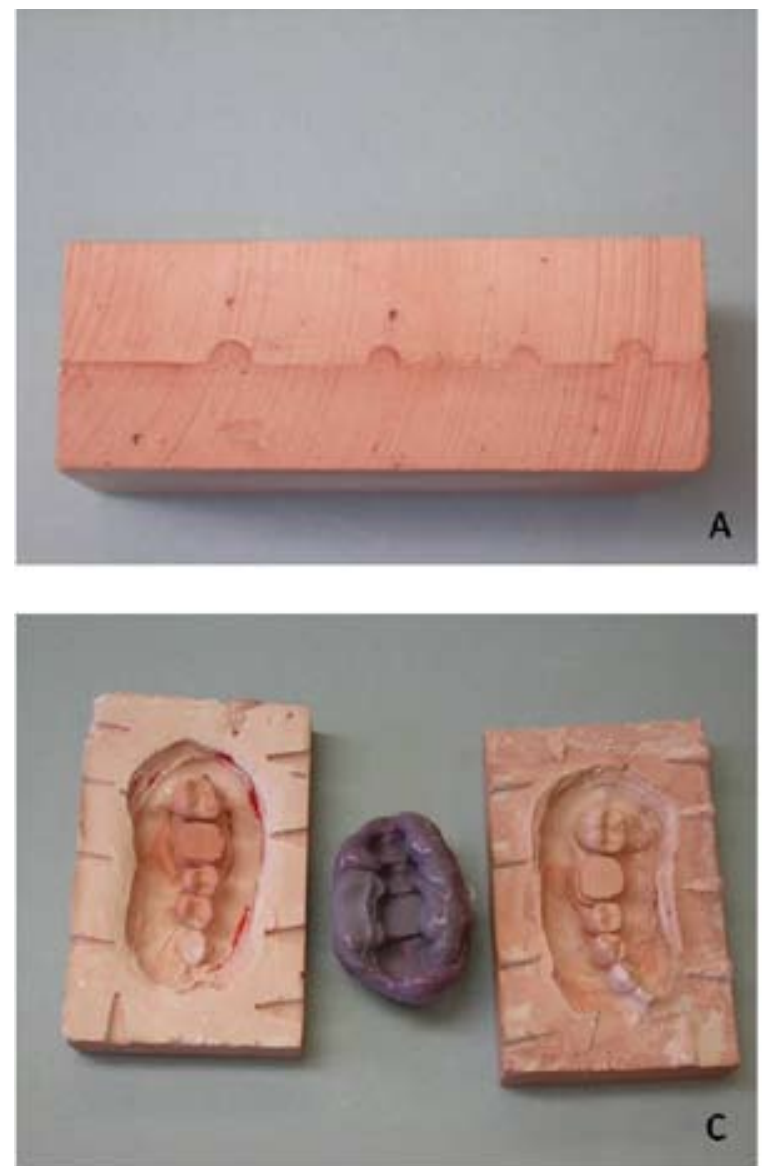

Fig. 2. Plaster brace and polyether impression die, which is what we will study taken a photograph and the five random measurements. the opposite side, leaving a plaster brace (Fig.2A).When opening this brace and removing the tray, it leaves a free space, which is what we will have to study.

In order to know the exact interocclusal length of such space, we proceed to fill the space with Permadyne ${ }^{\circledR}$ Penta $\mathrm{H}$ polyether made of Pentamix 3M. We let it dry for 10 minutes under a constant and reproducible pressure of $1 \mathrm{Kg}$ (Fig.2B). When opening the plaster brace again, we find a polyether impression die, which is what we will study (Fig.2C).

A vestibular to lingual cut is made on this impression die. This cut is magnified 10 times under a microscope and photographed with a Nikon ${ }^{\circledR}$ Coolpix camera at 3.5 zoom. Five random measurements are carried out based on these photos (Fig.2D), with the measuring tool of the PowerPoint program (Microsoft Windows Office 2003).

The ghost model is taken as a sample, making $3 \mathrm{im}$ pressions of the interocclusal space with Permadyne ${ }^{\circledR}$ in order to obtain an impression die so that we can make the corresponding 5 measurements.

\section{A}

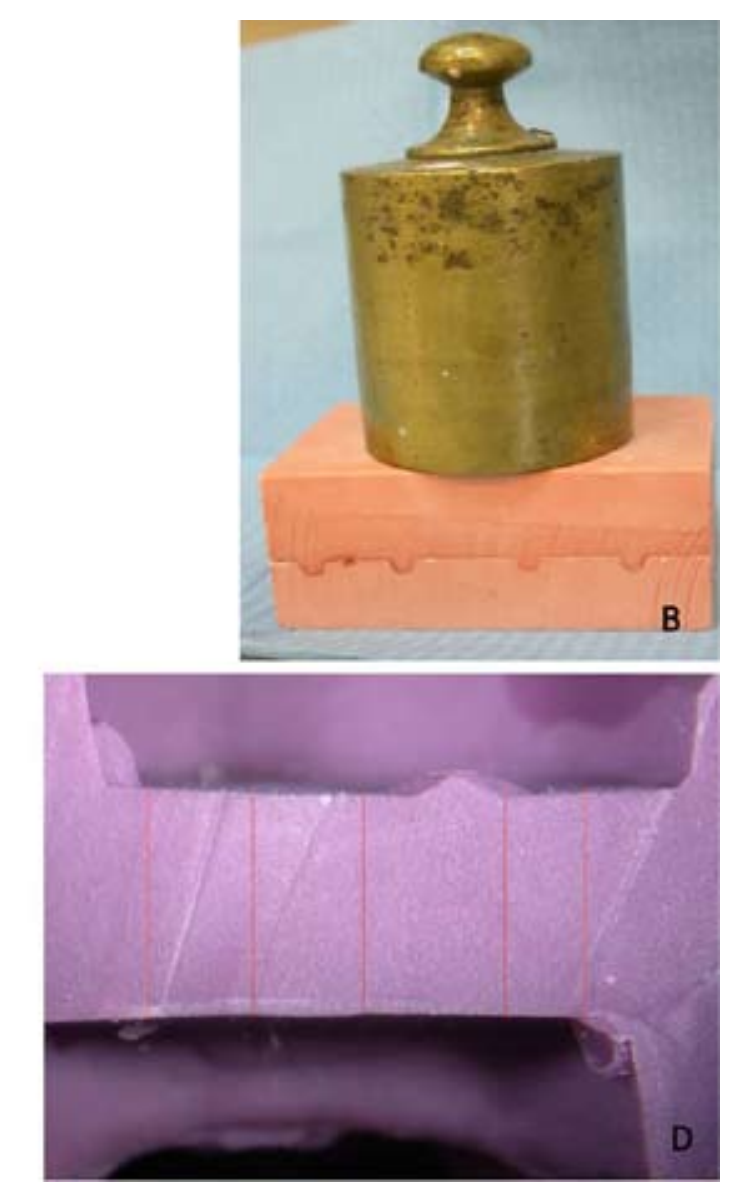




\section{Results}

In relationship to the variable of the type of tray, in table 1 we observe the results of the measurements taken on the polyether impression dies obtained during the processing of each specimen. Three silicone impressions and three polyether impressions were obtained for each tray, which gave a total of 6 impressions, and five measurements were recorded for each impression. An "average value" was calculated based on all of the values obtained, which is what defines each type of tray, in order to be able to compare them with each other. The same was done with the original sample obtained from the ghost model.

All of the trays studied show a slight increase in the interocclusal distance, which is not statistically significant in this study.

With the tray from Big Bite Tray ${ }^{\circledR}$ a value of 4.76 was obtained with the silicone material, whereas a value of 4.52 was obtained with the polyether. A value of 4.73

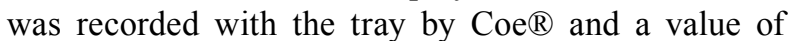
4.38 with the polyether tray. The tray by Multy-Tray ® showed values of 5.11 and 4.61 for the silicone and polyether trays respectively. Values of 4.50 and 4.71 are observed for the tray by Premier ${ }^{\circledR}$, whereas for the Bite Tray ${ }^{\circledR}$, values of 4.91 were observed for the silicone tray and 4.53 for the polyether tray. The values of the sample have a common average of 4.14 (Fig.3).

The results obtained can best be observed in the table, in which the value of the tray that comes closest to the original value or sample is the Coe ${ }^{\circledR}$ from the manufacturer $\mathrm{GC}$, followed by the Triple Tray ${ }^{\circledR}$ made by the manufacturer Premier. The tray that has the most distortion or most inter-maxillary space is the Multy Tray ${ }^{\circledR}$ (Fig. 4).

The other variable to be studied, that of the impression material, indicates that the material with the least amount of distortion is the polyether made by the manufacturer $3 \mathrm{M} \AA$, compared to the addition silicone material made by the manufacturer Zermack ${ }^{\circledR}$ (Fig. 5).

\section{Discussion}

When selecting the use of the dual-arch impression, it is recommended that dental professionals limit its application to one or two restorations. Even under this condition, the dental professional may want to provide the laboratory with some models of complete-arch impressions in order to enable contralateral symmetry. The success obtained with the dual-arch impression technique depends on how familiar the technician is with the laboratory procedures, especially those that are critical to managing the occlusion (5).

The dentist must take into account that the dual-arch trays are shallower. Some of the trays do not have sides; therefore, the dentist will not be able to obtain an impression of the soft tissue surrounding the carved tooth, and the technician will have some difficulty when emp- tying the tray, which can be avoided by making a cover for the tray. The reason that the dual impression tray is rather shallow is because we need to prevent distortion of the tray that occurs when hitting against the alveolus or the roof of the mouth. In fact, some trays do not have any sides. An acceptable alternative to avoid the use of models that are quite shallow, as already recommended, may be to cover the impression before emptying the working model; however, research is still required in order to find a technique for using deep casts without causing distortion of the impression (5).

There are different studies that analyze the exactness of the models obtained through the use of dual-arch trays, such as the study carried out by Lane et al. (5) in 2003, comparing the complete-arch impressions and the dualarch impressions in order to obtain indirect restorations. Through their study, they arrived at the conclusion that no significant differences are noted in the quality of the restorations produced by either technique. In a study conducted by Larson et al. (6), they consider the exactness of the use of the dual-arch trays in comparison with the complete-arch individual trays, and arrive at the conclusion that there are no differences between the models obtained; however, albeit not very significantly, the exactness does appear to be reduced when a dualarch tray is used, particularly when such tray is subject to bending at the time of taking the impression.

In a study conducted by Parker et al. (4), they showed that the dual-arch impression produces mounted models with an intercuspal relationship that is significantly more exact than the models produced by a completearch impression, being that the complete-arch impression is larger than that produced by the dual-arch technique. This error not only appears vertically, but was also observed horizontally, producing variation in the models obtained from the full arch impression trays.

Breeding et al. (7) arrived at the conclusion that the plastic trays produced replicas of teeth that were larger than the teeth for which they had taken the impression (95 and $166 \mu \mathrm{m}$ ) and the metallic trays produced replicas that were smaller $(-24$ and $-36 \mu \mathrm{m})$. Yet, in contrast with our results, they did not observe significant differences with respect to the exactness between the different materials used in their study: polyvinyl xylosan and polyether.

In the studies conducted by Ceyhan et al. (8-9), they analyze both the impression material as well as the trays. They recommend using the dual-arch trays compared to that of the complete-arch trays. Within the range of dual-arch trays, they prefer to use a rigid plastic material, such as that of polyether. The results of this author are very similar to the results that we obtained in our study.

In the study conducted by Cayouette et al. (10), they arrive at the same conclusion as we did in our study; that 


\section{Results}

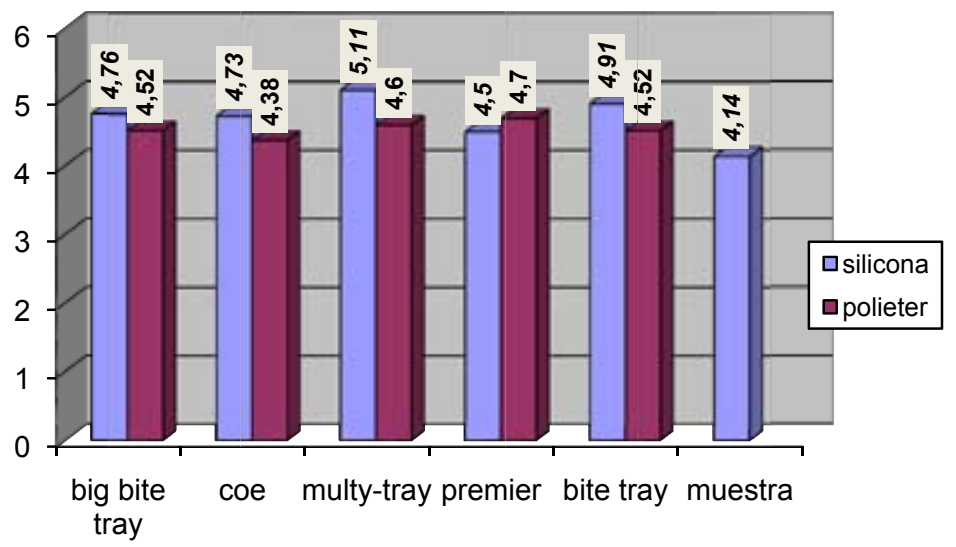

Resultados: results; Silicona: silicone; Polieter: polyether

Fig. 3. Comparative values between the two types of impression material.

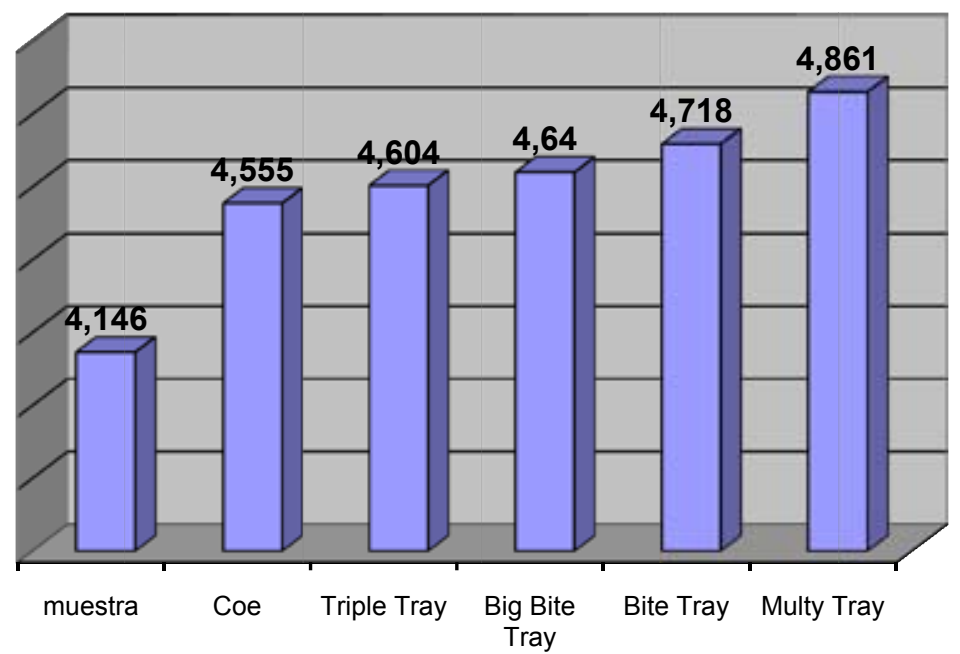

Fig. 4. Average distortion values of the interocclusal space.

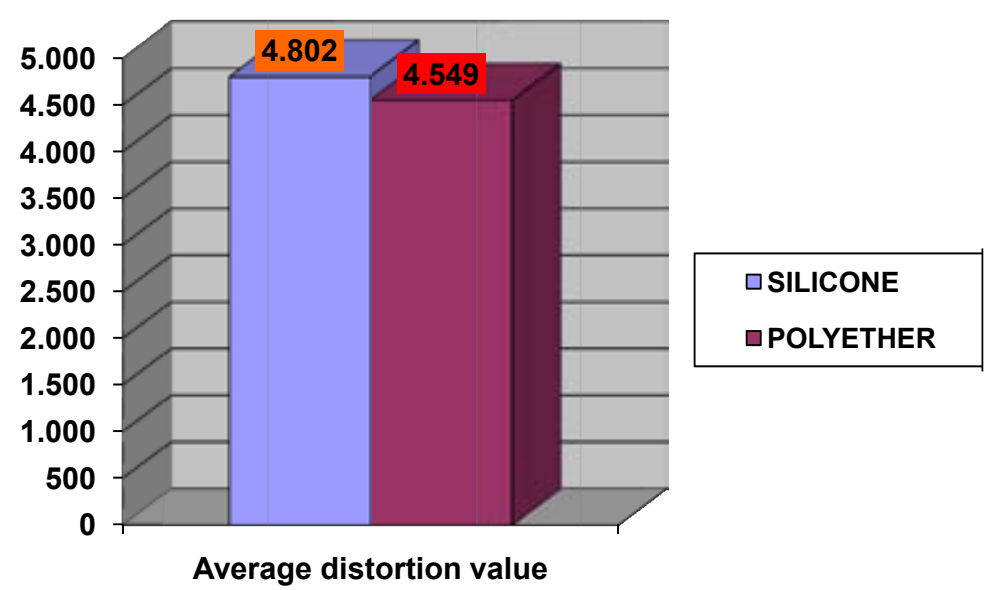

Fig. 5. Difference between silicone and polyether in terms of the average value of interocclusal distortion. 
Table 2. Characteristics of the trays.

\begin{tabular}{|c|c|c|c|c|c|}
\hline & Mesial- distal design & Lateral part & Inner part & Outer surface & Dividing membrane \\
\hline $\begin{array}{l}\text { TRIPLE TRAY } \\
\left.\text { (Premier }{ }^{\circledR}\right)\end{array}$ & Curve & High & Openings & Extension & $\begin{array}{l}\text { Frame made of a } \\
\text { very fine material }\end{array}$ \\
\hline $\begin{array}{l}\text { MULTI TRAY } \\
\text { (Henry Shein } ®)\end{array}$ & Curve & Low & Openings & Extension & Plastic \\
\hline $\begin{array}{l}\text { COE } \\
(G C \circledast)\end{array}$ & Curve & High & No openings & Extension & $\begin{array}{l}\text { Frame made of a fine } \\
\text { material }\end{array}$ \\
\hline $\begin{array}{l}\text { BITE TRAY } \\
(\mathrm{R \& S} \AA)\end{array}$ & Straight & High & No openings & No extension & Rigid gauze \\
\hline $\begin{array}{l}\text { BIG BITE TRAY } \\
\left.\text { (Bossworth }{ }^{\circledR}\right)\end{array}$ & Curve & Low & No openings & No extension & Most flexible gauze \\
\hline
\end{tabular}

is, the preferred material in the dual-arch trays is polyether as opposed to that of polysiloxan.

There is a very limited bibliography of comparative studies that have been conducted on the different types of trays (11-12). In our study, although we cannot offer very statistically significant results, we may reflect on why one particular tray offers better results than another. In the table, we have described the design characteristics of each tray used in our study (Table 2).

The tray by $\mathrm{COE}$ (GC® GC America INC.Alsip) and that of the Triple Tray (Premier ${ }^{\circledR}$, Premier Dental Products Co. Canada) give results that are very similar, given the similarity of these two designs. In our study, a very influential factor was the frame or dividing membrane that holds the impression material and is where the occlusion is made. The best values were obtained by the trays whose frame is very fine and does not prevent or provoke distortions when making the occlusion. The third tray that obtained good values was the Big Bite Tray ${ }^{\circledR}$ (Bossworth ${ }^{\circledR}$ Bosworth Co. England), which gives us reason to affirm that a frame that is not rigid, allowing the patient to make the occlusion correctly, will produce better results than a rigid or plastic frame. In considering the results obtained during our study, we can conclude that the use of this type of tray is highly recommended, provided it is used for the clinical conditions for which it was designed. Both according to our clinical experience as well as the best results that were obtained during our study, the trays that have a very fine frame made of either silicone or polyether are the most recommended, including the tray $\mathrm{COE}(\mathrm{GC} \circledast \mathrm{BC}$ America INC. Alsip) followed by the Triple Tray (Premier ${ }^{\circledR}$, Premier Dental Products Co. Canada).

When comparing the two impression materials, and always considering the results of our study, we observe that the material that produces the least interocclusal distortion is polyether, as opposed to addition silicone.

\section{References}

1. Pensler AV. Combined bite and impression technique. Dent Dig. 1971;77:454-8.

2. Burke FJ, Crisp RJ. A practice-based assessment of the handling of a fast-setting polyvinyl siloxane impression material used with the dual-arch tray technique. Quintessence Int. 2001;32:805-10.

3. Wilson EG, Werrin SR. Double arch impressions for simplified restorative dentistry. J Prosthet Dent. 1983;49:198-202.

4. Parker MH, Cameron SM, Hughbanks JC, Reid DE. Comparison of occlusal contacts in maximum intercuspation for two impression techniques. J Prosthet Dent. 1997;78:255-9.

5. Lane DA, Randall RC, Lane NS, Wilson NH. A clinical trial to compare double-arch and complete-arch impression techniques in the provision of indirect restorations. J Prosthet Dent. 2003;89:141-5.

6. Larson TD, Nielsen MA, Brackett WW. The accuracy of dual-arch impressions: a pilot study. J Prosthet Dent. 2002;87:625-7.

7. Breeding LC, Dixon DL. Accuracy of casts generated from dualarch impressions. J Prosthet Dent. 2000;84:403-7.

8. Ceyhan JA, Johnson GH, Lepe X. The effect of tray selection, viscosity of impression material, and sequence of pour on the accuracy of dies made from dual-arch impressions. J Prosthet Dent. 2003;90:143-9.

9. Ceyhan JA, Johnson GH, Lepe X, Phillips KM. A clinical study comparing the three-dimensional accuracy of a working die generated from two dual-arch trays and a complete-arch custom tray. J Prosthet Dent. 2003;90:228-34.

10. Cayouette MJ, Burgess JO, Jones RE Jr, Yuan CH. Three-dimensional analysis of dual-arch impression trays. Quintessence Int. 2003;34:189-98.

11. Cox JR, Brandt RL, Hughes HJ. A clinical pilot study of the dimensional accuracy of double-arch and complete-arch impressions. J Prosthet Dent. 2002;87:510-5.

12. Larson TD, Nielsen MA, Brackett WW. The accuracy of dualarch impressions: a pilot study. J Prosthet Dent. 2002;87:625-7. 